\title{
Ischemia Induces Partial Loss of Surface Membrane Polarity and Accumulation of Putative Calcium lonophores
}

\author{
Bruce A. Molitoris, Patricia D. Wilson, Robert W. Schrier, and Francis R. Simon \\ Divisions of Nephrology and Gastroenterology, Department of Medicine, University of Colorado School of Medicine, \\ Veterans Administration Medical Center, Denver, Colorado 80220
}

\begin{abstract}
To determine if ischemia induces alterations in renal proximal tubule surface membranes, brush border (BBM) and basolateral membranes (BLM) were isolated simultaneously from the same cortical homogenate after $50 \mathrm{~min}$ of renal pedicle clamping. Ischemia caused a selective decrease in the specific activity of BBM marker enzymes leucine aminopeptidase and alkaline phosphatase, but did not effect enrichment (15 times). Neither specific activity nor enrichment (10 times) of BLM NaK-ATPase was altered by ischemia. Contamination of BBM by intracellular organelles was also unchanged, but there was an increase in the specific activity (41.1 vs. 60.0, $P<0.01)$ and enrichment $(2.3$ vs. 4.3, $P<0.01$ ) of NaK-ATPase in the ischemic BBM fraction. Ischemia increased BLM lysophosphatidylcholine (1.3 vs. $2.5 \%$, $P<0.05)$ and phosphatidic acid $(0.4$ vs. $1.3 \%, P<0.05)$. Ischemia also decreased BBM sphingomyelin (38.5 vs. $29.6 \%, P$ $<0.01)$ and phosphatidylserine (16.1 vs. $11.4 \%, P<0.01)$, and increased phosphatidylcholine (17.2 vs. $29.7 \%, P<0.01)$, phosphatidylinositol (1.8 vs. $4.6 \%, P<0.01)$, and lysophosphatidylcholine (1.0 vs. 1.8\%, $P<0.05)$. The large changes in BBM phospholipids did not result from new phospholipid synthesis, since the specific activity $\left({ }^{32} \mathbf{P} \mathrm{dpm} / \mathrm{nmol} \mathbf{P i}\right)$ of prelabeled individual and total phospholipids was unaltered by ischemia. We next evaluated if these changes were due to inability of ischemic cells to maintain surface membrane polarity. Cytochemical evaluation showed that while NaK-ATPase could be detected only in control BLM, specific deposits of reaction product were present in the BBM of ischemic kidneys. Furthermore, using continuous sucrose gradients, the enzymatic profile of ischemic BBM NaKATPase shifted away from ischemic BLM NaK-ATPase and toward the BBM enzymatic marker leucine aminopeptidase. Taken together, these data suggest that NaK-ATPase activity determined enzymatically and cytochemically was located within ischemic BBM. We propose that ischemia impairs the ability of cells to maintain surface membrane polarity, and also results in the accumulation of putative calcium ionophores.
\end{abstract}

\section{Introduction}

Many theories have been advanced proposing a central role for plasma membrane damage in the pathogenesis of ischemic-in-

This work was presented in part at the 17th Annual Meeting of the American Society of Nephrology, Washington, DC, 1984.

Address reprint requests to Dr. Molitoris, Box C-280, University of Colorado.

Received for publication 18 March 1985 and in revised form 8 August 1985.

The Journal of Clinical Investigation, Inc.

Volume 76, December 1985, 2097-2105 duced cellular injury. Biochemical verification of these theories, however, is lacking. Several lines of evidence indicate the plasma membrane of renal proximal tubule cells is altered during ischemia. Morphologic studies have documented brush border membrane (BBM) ${ }^{1}$ interiorization and loss into the lumen (1). The extent of BBM damage and time necessary for BBM restoration correlated with the duration of ischemia (2). Physiologic alterations implicating surface membrane dysfunction include loss of selective permeability (2), and reductions in proximal tubular fluid reabsorption (3), sodium and glucose transport (4), and in potential difference (3).

Biochemical data regarding membrane damage during ischemia has primarily been nonspecific by determining total cellular and not organelle selective changes. Matthys et al. (5) have recently reported ischemia induced-increases in total cellular free fatty acids, diacylglycerol, lysophosphatidylcholine, and phosphatidic acid, and decreases in phosphatidylcholine and phosphatidylinositol. Siegel et al. (6) showed that ${ }^{14} \mathrm{C}$-choline incorporation into total cellular phospholipids more than doubled in an in vitro (cortical slice) and in vivo ischemia model of ischemia. Experimental evidence from other ischemic $(7,8)$ and nonischemic (9) organ models have also implicated a role for phospholipid degradation in liver (7), myocardium (8), and cultured fibroblasts (9) in cellular injury..

That renal BBM may be involved was suggested by Paddock et al. (10). Using a 25-min clamp model they demonstrated a loss of BBM enzymatic activity, decreased incorporation of ${ }^{3} \mathrm{H}$ leucine into BBM proteins, and a twofold increase in ${ }^{14} \mathrm{C}$-choline incorporation into BBM phospholipids. The potential importance of alterations in surface membrane phospholipids relates to the importance of phospholipids in determining and regulating membrane function. Since phospholipid composition is known to regulate intrinsic membrane enzymes $(11,12)$, ion and solute transport $(13,14)$, alterations in BBM, or basolateral membrane (BLM) phospholipid could play an important role in the pathogenesis of ischemic-induced cellular injury and dysfunction. The purpose, therefore, of the present studies was to determine if the lipid composition of renal proximal tubule BBM and or BLM was altered during ischemia.

\section{Methods}

Treatment of rats. Male Sprague-Dawley rats (King, Harland, and Sasco), weighing $220-260 \mathrm{~g}$, were fasted overnight before induction of ischemia or injection of radioactive compounds. $50 \mathrm{~min}$ of unilateral ischemia was induced, while under anesthesia with sodium pentobarbitol $(50 \mathrm{mg} /$ kg body weight), by clamping (Schwartz clip) the left renal pedicle after removal of the capsule. The right kidney, which was also decapsulated, served as the control. After placement of the clamp, a two layer closure

1. Abbreviations used in this paper: BBM, brush border membrane; BLM, basolateral membrane. 
was carried out, and $2 \mathrm{ml}$ of normal saline was injected intraperitoneally. To avoid any reflow, the clamp was left in place until the kidney was removed for processing.

Preparation and characterization of plasma membranes. Renal cortical BBM and BLM were prepared simultaneously from the same cortical homogenate of individual rats, as we have previously described in detail (15), with one modification. Briefly, after 50 min of ischemia, both kidneys were rapidly removed and placed in chilled buffer $(300 \mathrm{mM}$ mannitol, $5 \mathrm{mM}$ EGTA, $18 \mathrm{mM}$ Tris- $\mathrm{HCl}$, and $0.1 \mathrm{mM}$ PMSF at $\mathrm{pH}$ 7.4). Thin cortical sections were immediately obtained, minced, and suspended in $15 \mathrm{ml}$ of buffer using a 20 - $\mathrm{ml}$ syringe fitted with a 10-cm 16-gauge needle. The resulting solution was centrifuged for $30 \mathrm{~s}$ at $121 \mathrm{~g}$ using a Sorvall SS 34 rotor. The supernatant was discarded and the pellet underwent the same procedure until the supernatant became clear, which usually required a total of three or four centrifugation steps. This modification was necessary to remove excess erythrocytes from the ischemic kidney (16), but was applied to both control and experimental kidneys.

To the resulting pellet, $15 \mathrm{ml}$ of buffer was added, and homogenization was accomplished using a Polytron PT 200D (Brinkman Co.) (15). The homogenate was diluted with $21 \mathrm{ml}$ of distilled water and centrifuged at $48,000 \mathrm{~g} \times 30 \mathrm{~min}$. The resulting pellet $(\mathrm{Pi})$ was resuspended, and $\mathrm{Mg}^{2+}$ precipitation ( $15 \mathrm{mmol} / \mathrm{liter}$ ) was carried out for $20 \mathrm{~min}$. This solution was centrifuged for $15 \mathrm{~min}$ at $2,445 \mathrm{~g}$. The pellet $\left(\mathrm{P}_{2}\right)$ was saved for basolateral membrane isolation while the supernatant was centrifuged at $48,000 \mathrm{~g} \times 30 \mathrm{~min}$ to obtain the crude BBM. This pellet was resuspended using a Potter-Elvejhem teflon glass homogenizer in $30 \mathrm{ml}$ of diluted buffer (1:1 with deionized water), taken through the $\mathrm{Mg}^{2+}$ precipitation process again, and washed free of $\mathrm{Mg}^{2+}$ using resuspension with the Potter-Elvejhem homogenizer and centrifuged at $48,000 \mathrm{~g}$ for $30 \mathrm{~min}$.

The basolateral membrane was isolated from the initial $\mathrm{Mg}^{2+}$ precipitation pellet $\left(\mathrm{P}_{2}\right)$. This pellet was resuspended in diluted buffer using a loose Dounce homogenizer (10 strokes) followed by repeat addition of $\mathrm{Mg}^{2+}(15 \mathrm{mM})$ with intermittent shaking for $20 \mathrm{~min}$, and then centrifugation at $2,445 \mathrm{~g} \times 15 \mathrm{~min}$. The pellet $\left(\mathbf{P}_{3}\right)$ was resuspended in standard buffer, diluted with water (1:1), and centrifuged for $15 \mathrm{~min}$ at $755 \mathrm{~g}$. The supernatant was centrifuged for $30 \mathrm{~min}$ at $48,000 \mathrm{~g}$ and the resulting pellet $\left(\mathrm{P}_{5}\right)$ was resuspended in $19 \mathrm{ml}$ of $50 \%$ sucrose with a Potter-Elvejhem homogenizer. The sample was overlayed with a discontinuous sucrose gradient using $41 \%(5 \mathrm{ml})$ and $38 \%(12 \mathrm{ml})$ in celluloseacetate-tubes and centrifuged for $3 \mathrm{~h}$ at $88,000 \mathrm{~g}$ in a model L8-70 ultracentrifuge (Beckman Instruments, Inc., Fullerton, CA) using a swinging bucket SW 28 rotor. The top layer (38\%) was harvested, resuspended in $1 \mathrm{mM}$ bicarbonate, and centrifuged at $48,000 \mathrm{~g} \times 30 \mathrm{~min}$. Both the final $B B M$ and BLM were resuspended in $1-1.5 \mathrm{ml}$ of buffer and stored at $-20^{\circ} \mathrm{C}$.

Enzyme and protein measurements. Protein was measured according to Lowry et al. (16) using bovine serum albumin (BSA) as a standard. Enzyme determinations were carried out as previously reported from our laboratory (15).

Lipid determinations. The lipids from $0.5-1 \mathrm{mg}$ of membrane protein were extracted in $6 \mathrm{ml}$ of chloroform/methanol (1:2 vol/vol) and isolated by the Bligh and Dyer procedure (18). Free cholesterol was quantitated by gas-liquid chromatography as previously described (15) using coprostenol as an internal standard for cholesterol recovery and quantification (15). Total phospholipids were determined on an extract according to Ames and Dubin (19). Individual phospholipid species were identified using a brief exposure to iodine vapor, scraped off the plates, and extracted as previously described (15). The Pi from individual phospholipid species was determined by the method of Ames and Dubin (19) on an aliquot. We have previously shown this procedure results in excellent recovery and purification of all phospholipid species (15)

Radioisotopic labeling of phospholipids. To label surface membrane phospholipids, $1 \mathrm{mCi}$ of ${ }^{32} \mathrm{P}$ (orthophosphate, New England Nuclear, Boston, MA) was injected intraperitoneally into fasting animals $72 \mathrm{~h}$ before induction of ischemia. We have previously determined that $72 \mathrm{~h}$ is required for all species of surface membrane phospholipids to enter into the isotopic decay phase (20). The specific activity of individual phospholipids (dpm per micromole $\mathrm{Pi}$ ) was determined by liquid scintillation counting of an aliquot from the same sample used to determine phospholipid composition.

Electron microscope cytochemistry of NaK-ATPase. Rat kidneys made ischemic by $50 \mathrm{~min}$ renal pedicle clamping and contralateral unclamped control kidneys were sliced and the cortex fixed for $15 \mathrm{~min}$ at $4^{\circ} \mathrm{C}$ in $1 \%$ paraformaldehyde, $0.25 \%$ glutaraldehyde in $100 \mathrm{mM}$ sodium cacodylate buffer containing $5 \%$ sucrose, and snap frozen in $100 \mathrm{mM}$ Trisbuffer. Frozen cryostat sections cut at $50 \mu \mathrm{m}$ were incubated for $30 \mathrm{~min}$ at room temperature in media designed to localize NaK-ATPase (21). This media was comprised of $100 \mathrm{mM}$ Tris- $\mathrm{HCl}$ buffer ( $\mathrm{pH} \mathrm{9)}$ containing $5 \%$ sucrose, $20 \mathrm{mM} \mathrm{MgCl}_{2}, 10 \mathrm{mM} \mathrm{KCl}, 20 \mathrm{mM} \mathrm{SrCl}_{2}, 5 \mathrm{mM}$ sodium nitrophenyl phosphate as substrate, and $2.5 \mathrm{mM}$ levamisole to inhibit alkaline phosphatase activity. Dimethylsulfoxide (25\%) was added to some media as an activator (22). Controls contained $10 \mathrm{mM}$ ouabain, a specific inhibitor for NaK-ATPase. After incubation, tissue slices were washed four times for $5 \mathrm{~min}$ in Tris-HCl buffer, $\mathrm{pH} 9$, at $4^{\circ} \mathrm{C}$, postcoupled in $2 \%$ lead nitrate for two changes of $5 \mathrm{~min}$, rinsed for $5 \mathrm{~min}$ each in Tris/ $\mathrm{HCl}$ buffer, and postfixed for $30 \mathrm{~min}$ in $1 \%$ osmium tetroxide in $100 \mathrm{mM}$ sodium cacodylate buffer. After dehydration in graded ethanols and embedding in araldite, ultrathin sections were cut and viewed in a Philips 300 electron microscope either without poststaining or after staining with uranyl acetate or lead citrate.

Continuous sucrose gradients. Separation of previously isolated, but remixed, control BBM and BLM was examined using a 15-45\% continuous sucrose gradient. Control freshly isolated (standard procedure listed above) BBM and BLM fractions were mixed together, diluted 1:1 with $30 \%$ sucrose, and layered over the top of the continuous sucrose gradient. This solution was centrifuged at $88,000 \mathrm{~g}\left(5^{\circ} \mathrm{C}\right)$ for $16 \mathrm{~h}$ in a model L870 ultracentrifuge (Beckman Instruments Inc.) using a swinging bucket SW 28 rotor. 1-ml aliquots were harvested using an Auto Densi-Flow IIC (Buchler Instruments, Inc., Fort Lee, NJ), and standard kinetic enzymatic assays were performed for leucine aminopeptidase and $\mathrm{NaK}$ ATPase. The sucrose percentage of each tube was determined using a Bausch and Lomb refractometer. The ischemic BBM fraction underwent the identical procedure, except no BLM fraction was added before ultracentrifugation.

In addition, ischemic BBM, control, and ischemic BLM fractions were layered over separate $25-50 \%$ continuous sucrose gradients and taken through the same centrifugation and harvesting procedures.

Statistical analysis. A paired 2-tailed $t$ test was used to determine statistical significance unless otherwise indicated. Values were considered significantly different if the $P$ value was $\leq 0.05$, and were reported as NS, $<0.05$, and $<0.01$. All values are reported as the mean \pm 1 SD.

\section{Results}

Membrane isolation. The effect of ischemia on the specific activity of cellular enzymes is shown in Table I. $50 \mathrm{~min}$ of ischemia without reflow resulted in a $22 \%$ decrease $(P<0.01)$ in the specific activity of homogenate leucine aminopeptidase, a selective BBM marker enzyme, but had no significant effect on enzyme activities from other cellular organelles (NaK-ATPaseBLM; succinic dehydrogenase for mitochondrial; cytochrome $c$ reductase for endoplasmic reticulum; and glucosaminidase for lysosome). There was also a $21 \%(P<0.01)$ decrease in homogenate alkaline phosphatase, another enzymatic marker for the BBM. A similar decrease in leucine aminopeptidase (33\%, $P<0.01)$ and alkaline phosphatase $(27 \%, P<0.01)$ was noted in the ischemic BBM fraction. This suggests the BBM fraction isolated after ischemia is representative of what is occurring to the total brush border membrane. This view is supported by the similar, although slightly lower enrichments of leucine aminopeptidase and alkaline phosphatase from control and ischemic BBM fractions (Fig. 1). Also, there was no alteration in the percentage recovery of leucine aminopeptidase (33.2 \pm 7.2 vs. 
Table I. Effect of Ischemia on Cellular and BBM Enzyme Specific Activity

\begin{tabular}{|c|c|c|c|c|c|c|}
\hline & \multirow[b]{2}{*}{$n$} & \multicolumn{5}{|c|}{ Specific activity $\left(\mu \mathrm{mol} \cdot \mathrm{mg}\right.$ protein $\left.^{-1} \cdot h^{-1}\right)$} \\
\hline & & $\begin{array}{l}\text { Leucine } \\
\text { aminopeptidase }\end{array}$ & NaK-ATPase & $\begin{array}{l}\text { Succinic } \\
\text { dehydrogenase }\end{array}$ & $\begin{array}{l}\text { Cytochrome } c \\
\text { reductase }\end{array}$ & Glucosaminidase \\
\hline \multicolumn{7}{|l|}{ Homogenate } \\
\hline Control & 15 & $5.5 \pm 0.8$ & $17.0 \pm 4.7$ & $42.1 \pm 7.6$ & $2.4 \pm 0.7$ & $13.3 \pm 1.3$ \\
\hline Ischemic & 15 & $4.3 \pm 1.0$ & $15.6 \pm 3.7$ & $39.0 \pm 8.7$ & $2.2 \pm 0.5$ & $11.7 \pm 1.9$ \\
\hline$P$ value & & $\leq 0.01$ & NS & NS & NS & NS \\
\hline \multicolumn{7}{|c|}{ Brush border fraction } \\
\hline Control & 11 & $80.6 \pm 26.1$ & $41.1 \pm 11.8$ & $8.6 \pm 3.3$ & $1.6 \pm 0.4$ & $4.2 \pm 0.2$ \\
\hline Ischemic & 11 & $53.7 \pm 19.1$ & $60.9 \pm 15.5$ & $11.4 \pm 4.1$ & $1.9 \pm 0.7$ & $4.8 \pm 0.6$ \\
\hline$P$ value & & $\leq 0.01$ & $\leq 0.01$ & NS & NS & $\leq 0.05$ \\
\hline
\end{tabular}

Values are reported as the mean $\pm 1 \mathrm{SD} ; n$ refers to the number of individual preparations analyzed.

$32.5 \pm 5.5 \%$ ), again indicating that the BBM fraction isolated after ischemia can be compared with control BBM. Contamination of control and ischemic BBM fractions by intracellular organelles was not altered by ischemia, except for a minor increase in the enrichment of glucosaminidase $(0.32 \pm 0.02$ vs. $0.45 \pm 0.06, P$ $<0.01)$. There was, however, a significant increase in both the specific activity (Table I) and enrichment (Fig. 1) of NaK-ATPase in the ischemic BBM fraction. The recovery of protein increased $(2.0 \pm 0.8$ vs. $2.5 \pm 1.2 \%, P<0.01)$ after the ischemic insult.

The BLM fraction isolated after ischemia showed no change in the marker enzyme NaK-ATPase specific activity (133.6 \pm 46.8 vs. $144.7 \pm 39.6)$, enrichment $(8.2 \pm 3.2$ vs. $9.9 \pm 2.8)$, enzyme recovery $(25.1 \pm 10.9$ vs. $19.0 \pm 4.4 \%)$, or contamination from intracellular organelles. There was, however, a decrease in protein recovery $(1.8 \pm 0.7$ vs. $1.1 \pm 0.5 \%, P<0.01)$ and a slight increase in leucine aminopeptidase enrichment in ischemic BLM $(2.2 \pm 0.5$ vs. $3.0 \pm 0.6, P<0.05)$.

Surface membrane lipids. The changes in BBM and BLM phospholipids due to ischemia are shown in Table II and Fig. 2. Ischemia was without an effect on the major BLM phospholipids (Table II) or the cholesterol to phospholipid ratio $(0.51 \pm 0.01$ vs. $0.53 \pm 0.11)$. However, an increase in BLM phosphatidic acid and lysophosphatidylcholine did occur during ischemia (Fig. 2).
Ischemia resulted in large alterations in the BBM lipid composition (Table II). The cholesterol to phospholipid ratio decreased $(0.79 \pm 0.10$ vs. $0.63 \pm 0.06, P<0.05)$, while the individual phospholipids sphingomyelin and phosphatidylserine decreased, and phosphatidylcholine and phosphatidylinositol increased. Lysophosphatidylcholine also increased in ischemic BBM fractions $(1.0 \pm 0.5$ vs. $1.8 \pm 0.4 \%, P<0.05)$, while phosphatidic acid was unchanged. As these were large changes in phospholipid composition, we next set out to determine their etiology.

Phospholipid turnover. To investigate the effect of renal ischemia on phospholipid turnover, membrane phospholipids were labeled with ${ }^{32} \mathrm{P} 72 \mathrm{~h}$ before the induction of ischemia. As is shown in Fig. 3, specific activity of individual and total phospholipids from control and ischemic BBM fractions was not altered. The lack of change in specific activity of ischemic BBM phospholipids indicates that the change in phospholipid composition was not due to newly synthesized phospholipids diluting a prelabeled membrane pool. Altered phospholipid turnover, therefore, does not explain the changes in BBM phospholipid composition after renal ischemia.

Cytochemical localization of NaK-ATPase. To evaluate the possibility that loss of surface membrane polarity during ischemia may account for the changes in BBM composition, localization of NaK-ATPase was determined cytochemically in control and

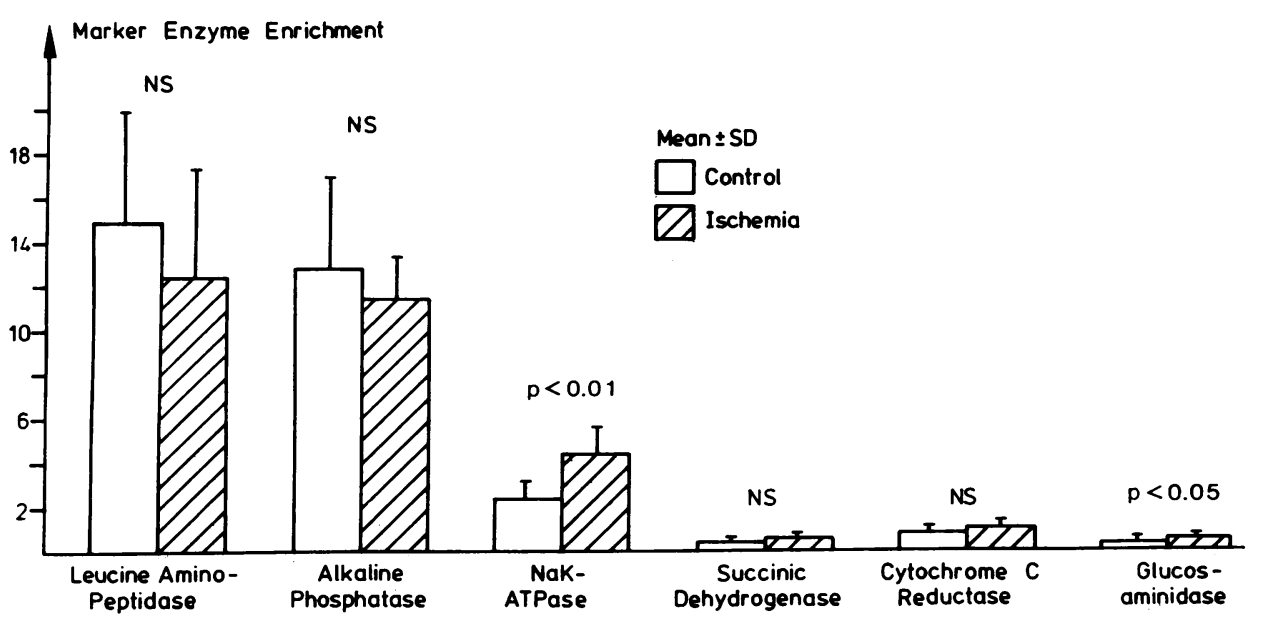

Figure 1. Effect of ischemia on BBM enzyme enrichment. BBM fractions were isolated as described in Methods. Marker enzyme enrichment is the ratio of the BBM specific activity divided by the specific activity of the homogenate. Leucine aminopeptidase and alkaline phosphatase are BBM enzymatic markers; NaKATPase, succinic dehydrogenase, cytochrome $c$ reductase, and glucosaminidase are enzymatic markers for BLM, mitochondria, endoplasmic reticulum, and lysosomes, respectively. $n=11$ for leucine aminopeptidase, alkaline phosphatase, and NaK-ATPase, and 7 for the remaining marker enzymes. Values are the mean $\pm 1 \mathrm{SD}$. 


\begin{tabular}{|c|c|c|c|c|c|c|}
\hline & \multirow[b]{2}{*}{$n$} & \multicolumn{5}{|c|}{ Total phospholipids (\%) } \\
\hline & & Sphingomyelin & P-Choline & P-Ethanolamine & P-Serine & P-Inositol \\
\hline \multicolumn{7}{|l|}{ Brush border } \\
\hline Control & 7 & $38.5 \pm 4.9$ & $17.2 \pm 2.6$ & $24.4 \pm 2.1$ & $16.1 \pm 1.6$ & $1.8 \pm 0.3$ \\
\hline Ischemic & 7 & $29.6 \pm 3.2$ & $29.7 \pm 2.3$ & $21.5 \pm 1.8$ & $11.4 \pm 0.6$ & $4.6 \pm 0.6$ \\
\hline$P$ value & & $\leq 0.01$ & $\leq 0.01$ & NS & $\leq 0.01$ & $\leq 0.01$ \\
\hline \multicolumn{7}{|l|}{ Basolateral } \\
\hline Control & 6 & $17.2 \pm 2.0$ & $36.7 \pm 1.6$ & $28.9 \pm 2.5$ & $9.2 \pm 0.6$ & $5.6 \pm 0.3$ \\
\hline Ischemic & 6 & $15.3 \pm 2.9$ & $35.2 \pm 3.5$ & $30.6 \pm 1.5$ & $9.1 \pm 1.0$ & $5.3 \pm 1.1$ \\
\hline$P$ value & & NS & NS & NS & NS & NS \\
\hline
\end{tabular}

$\mathrm{P}$, Phosphatidyl-. Values are reported as the mean $\pm 1 \mathrm{SD} ; n$ refers to the number of individual preparations analyzed.

ischemic proximal tubule cells. The results are shown in Figs. 4 and 5. NaK-ATPase reaction product, visualized as electron dense deposits of lead phosphate, were seen lining the basolateral plasma membrane infoldings of proximal tubules (Fig. $4 \mathrm{~A}$ ). This reaction was inhibited by the selective inhibitor ouabain (not shown). No ouabain-inhibitable reaction product was seen associated with the BBM microvilli of proximal tubules from normal kidneys (Fig. 4 B). In ischemic cells, however, the NaKATPase reaction product did appear in abnormally whirled membrane fragments of apical BBM (Fig. $5 A$ ), and this reaction was inhibited by the presence of ouabain (Fig. $5 B$ ). The NaKATPase reaction product in ischemic BLM was seen lining disorganized membrane infoldings and vesicles (not shown).

Membrane separation. The NaK-ATPase reaction product seen in the lumen of ischemic cells could also have resulted from fragments of BLM lost due to cellular disruption rather than loss of surface membrane polarity. To evaluate this possibility, a continuous sucrose gradient was used to separate previously isolated but remixed control BBM and BLM fractions. If the cytochemically localized $\mathrm{NaK}$-ATPase reaction product was due to separate free floating fragments of BLM, one would expect to find two separable BBM and BLM enzymatic activity profiles.

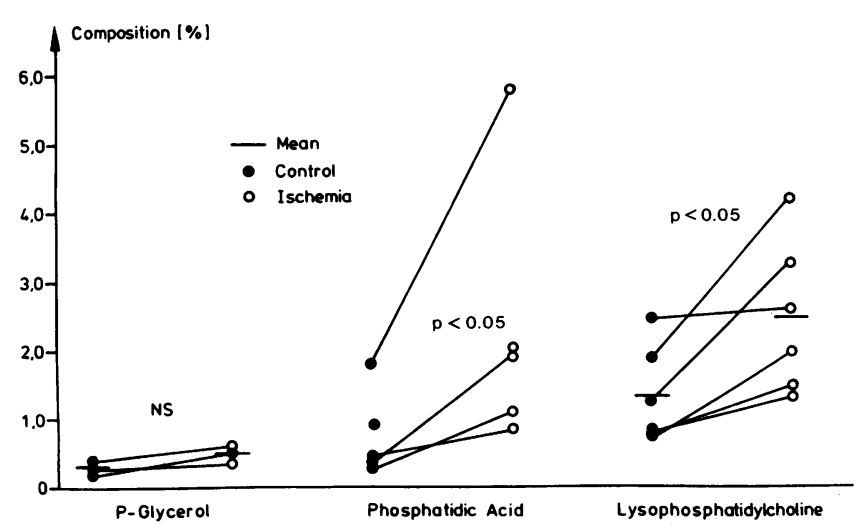

Figure 2. Effect of ischemia on BLM minor phospholipids. BLM fractions were isolated as described in Methods and phospholipids were separated by two-dimensional thin-layer chromatography. Values are reported as percentage of the recovered phospholipids. Statistical significance for phosphatidic acid was determined using the Wilcoxon signed rank test.
If loss of surface membrane polarity was the cause of the increase in BBM NaK-ATPase, one would expect overlapping enzyme profiles because the two marker enzymes are localized within the same membrane. The data in Fig. $6 \mathrm{~A}$ clearly show that the two surface membrane fractions can be separated in the control situation with the BLM enzyme marker (NaK-ATPase) maximal activity located at $35.5 \%$ sucrose and the BBM enzyme marker (leucine aminopeptidase) at $38.5 \%$. In contrast, as shown in Fig. $6 \mathrm{~B}$, the ischemic BBM components equilibrated as a single broader fraction. Since the enzymatic markers could not be separated in the ischemic BBM fraction, these data suggest that the membranes have a single density and are not two distinct populations.

Fig. 7 shows the effect of ischemia on the enzymatic profiles, obtained from sucrose density gradients, of both membrane fractions. The BBM profile of leucine aminopeptidase (Fig. 7 $B$ ) shifted to the left (peak 35.4), while the BLM NaK-ATPase profile (Fig. $7 A$ ) shifted to the right (peak 38.0\%). A control BLM fraction run at the same time had a peak for the NaKATPase profile at $36.2 \%$ (data not shown), which is in close agreement with the data in Fig. 6.

These data can also be used to evaluate if the NaK-ATPase

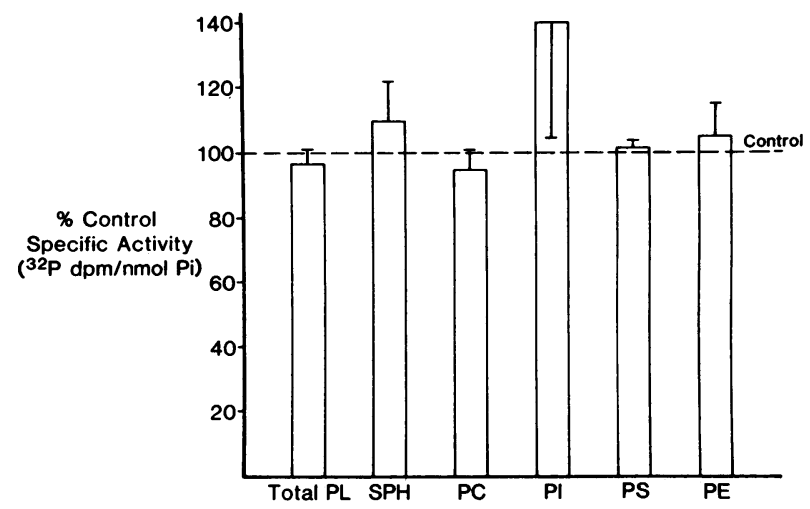

Figure 3. Effect of ischemia on BBM phospholipid specific activity (dpm per nanomole Pi). Values are expressed as a percent of contralateral control kidney values. Total PL, total phospholipids; SPH, sphingomyelin; PC, phosphatidylcholine; PI, phosphatidylinositol; PS, phosphatidylserine; and PE, phosphatidylethanolamine. $n=4$. Values are the mean $\pm 1 \mathrm{SD}$. 

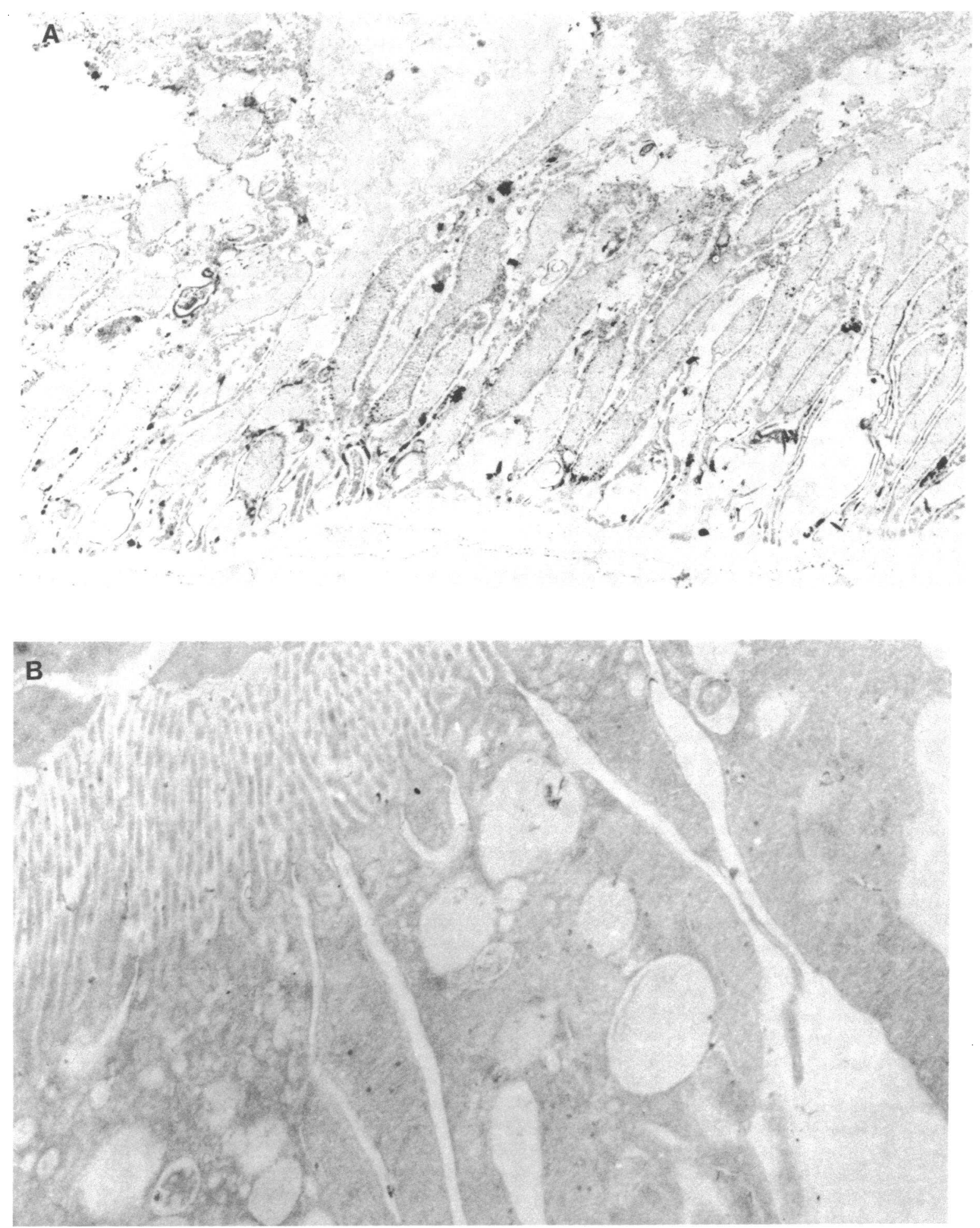

Figure 4. Cytochemical localization of NaK-ATPase in control proximal tubule cells. $A$ shows reaction product on the BLM. $\times 12,000$. $B$ shows that there is no reaction at the apical cell surface. $\times 24,000$.

present in the ischemic BBM fraction is due to loss of membrane polarity or contamination. If the NaK-ATPase activity within the ischemic BBM fraction was due to loss of polarity and migration of $\mathrm{NaK}-\mathrm{ATPase}$ into the BBM, one would expect the enzyme profiles of ischemic BBM NaK-ATPase and a BBM marker enzyme to be similar. Also, the activity profile of ischemic
BBM NaK-ATPase should be different (shifted away) from the profile for ischemic BLM NaK-ATPase. As is shown in Fig. 7 $B$, the ischemic BBM NaK-ATPase activity profile was very similar to the leucine aminopeptidase profile for the same membrane fraction. In contrast, it is distinctly different from the profile of NaK-ATPase activity in the ischemic BLM fraction (Fig. $7 A$ ). 

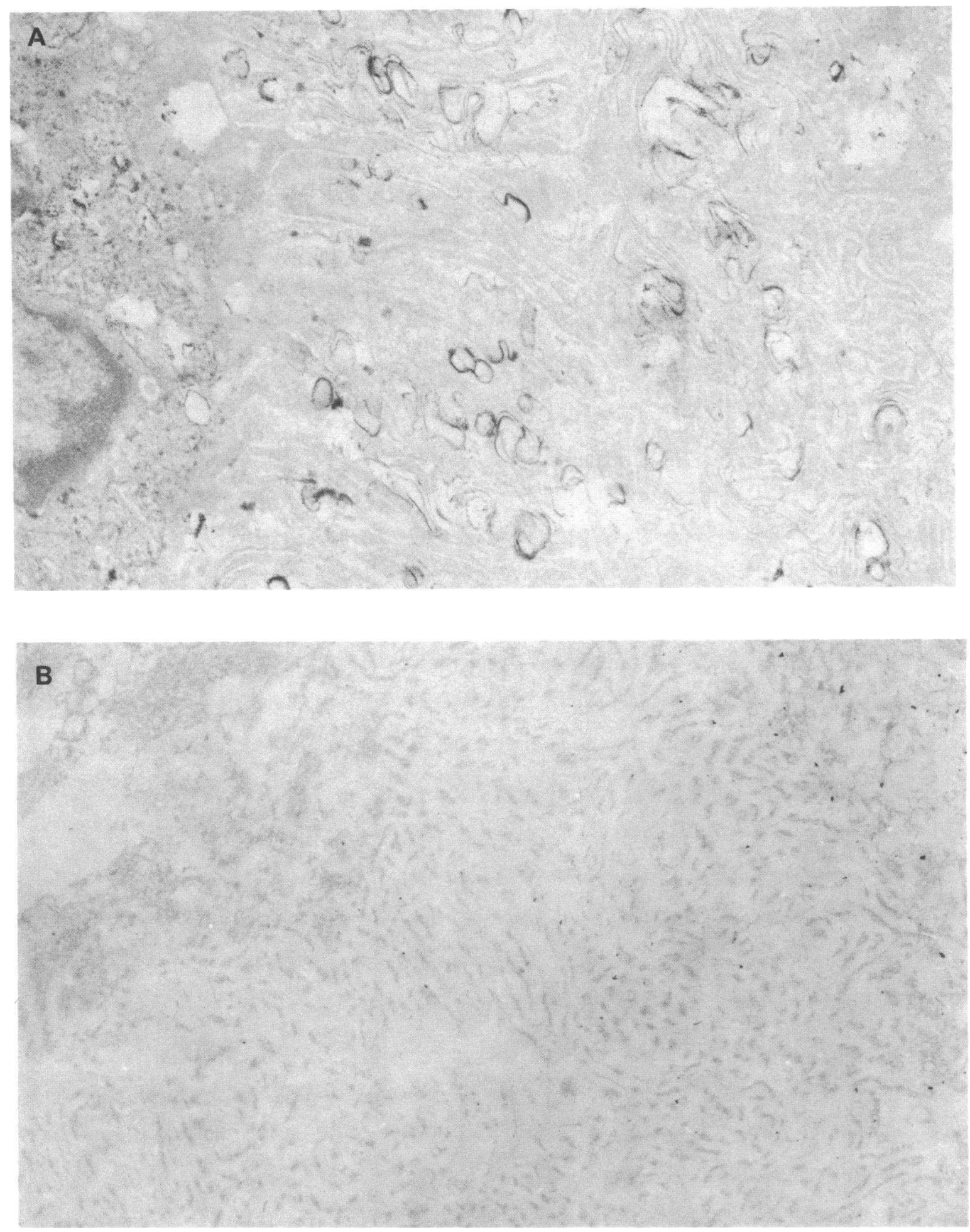

Figure 5. Cytochemical localization of NaK-ATPase in ischemic proximal tubule cells. $A$ shows reaction product at the disorganized ischemic BBM. $\times 28,000 . B$ shows that $10 \mathrm{mM}$ ouabain abolished the reaction at this site. $\times 28,000$.

Therefore, these data also suggest that loss of surface membrane polarity occurred during ischemia.

\section{Discussion}

Surface membrane alterations secondary to ischemia have been hypothesized to be involved in the cellular pathophysiology of ischemia in the kidney and other tissues. However, only morphologic and physiologic changes have been examined (1-4). The present studies, therefore, were undertaken to determine if the surface membrane of renal proximal tubule cells is altered during ischemia. The ability to isolate and individually characterize both the brush border and basolateral membrane (15) 

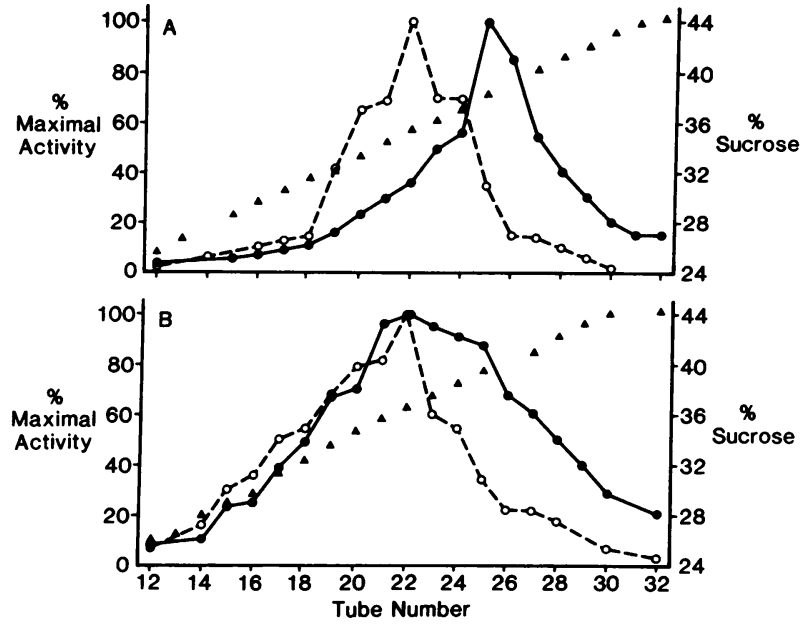

Figure 6. Separation of surface membrane components: effect of ischemia. Open circles with a dashed line and closed circles with a solid line represent the percentage of maximal activity of NaK-ATPase and leucine aminopeptidase, respectively. The closed triangles are used to indicate the sucrose gradient. Samples were collected as consecutive 1$\mathrm{ml}$ fractions starting at the top (15\%) of the sucrose gradient. $(A)$ Control previously isolated and remixed control BBM and BLM components. (B) Ischemic BBM fraction.

makes the rat kidney a particularly interesting and relevant organ to study.

Adaptation of our previously described method for the simultaneous isolation of BBM and BLM from the same homogenate involved only a single additional step to remove excessive erythrocytes before homogenization. As previously reported for Flounder kidney (16), this step reduces erythrocyte ghost contamination of the BBM fraction. Because of marked differences in protein and phospholipid composition of the two membranes, erythrocyte contamination would cause apparent changes. Equal marker enzyme enrichment (Fig. 1), recovery, and labeling of individual phospholipids (Fig. 3) for control and ischemic BBM fractions, however, are all consistent with removal of erythrocytes by the initial centrifugation steps.

Since equal enrichments of BBM and BLM marker enzymes
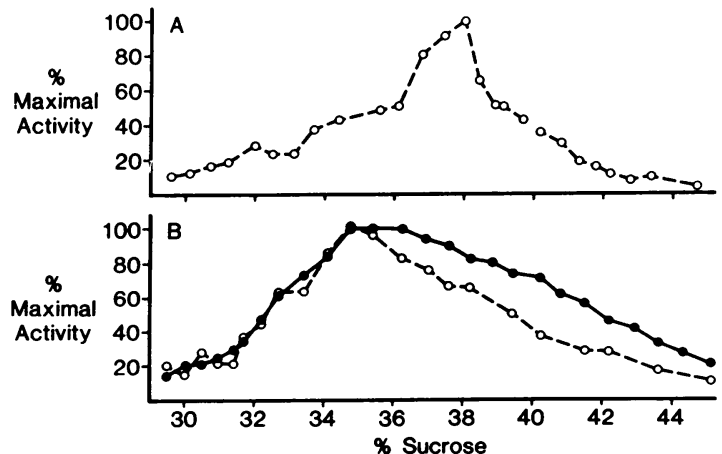

Figure 7. Effect of ischemia on the density profile of BBM and BLM. Open circles with a dashed line and closed circles with a solid line represent the percentage of maximal activity of NaK-ATPase and leucine aminopeptidase, respectively. Samples were collected as consecutive 1$\mathrm{ml}$ fractions starting at the top $(25 \%)$ of a $25-50 \%$ sucrose gradient. $(A)$ Ischemic BLM fraction. $(B)$ Ischemic BBM fraction. in control and ischemic BBM and BLM fractions were achieved, a comparison of the results from control and ischemic kidneys was reasonable. Also, contamination from intracellular organelles was not altered by ischemia. The increased BBM protein recovery and decreased BLM recovery in ischemia, although of initial concern, were observations that were compatible with the loss of surface membrane polarity (infra vide).

In this reversible model of ischemia (23) without reflow, there seemed to be selective loss of BBM proteins, since the activity of BBM marker enzymes was decreased in both the BBM fraction and homogenate, and all other measured cellular enzymatic markers were unaffected (Table I). Although there was no change in the BLM marker enzyme NaK-ATPase, there was, however, an alteration in BLM phospholipids during ischemia. Significant increases in both phosphatidic acid and lysophosphatidylcholine were noted. These data are in agreement with the cellular homogenate results of Mattys et al. (5). The present results extend their observation and indicate that these potentially toxic phospholipids accumulate in the BLM during ischemia. The role of lysophosphatidylcholine and phosphatidic acid in increasing membrane permeability to calcium has been established. in several systems $(13,24,25)$. It seems, therefore, that ischemia results in the abnormal accumulation of putative calcium ionophores in the BLM of proximal tubule cells. Whether or not this leads to increased calcium influx during reflow was not determined in these studies, but the reported phospholipid alterations are compatible with this hypothesis.

The ischemia-induced alterations in the lipid composition of the BBM were evaluated next. Three possible mechanisms to explain these changes were investigated, and include ischemiainduced alterations in (1) phospholipid turnover, (2) surface membrane polarity, and (3) the ability to separate BBM and BLM after ischemia. To determine the etiology of these changes, we first set out to evaluate the role of altered phospholipid synthesis and degradation. It seemed unlikely that such large increases in phosphatidylcholine, phosphatidylinositol, and decreases in sphingomyelin, phosphatidylserine, and cholesterol could occur in a situation where cellular ATP was extremely low. If altered turnover of phospholipids was responsible for the compositional changes reported, one would have expected the specific activity of total and individual phospholipid classes to be reduced as new unlabeled phospholipids moved into the BBM and diluted the preexisting labeled phospholipids. This holds only if the phospholipids were in the isotopic decay phase. Therefore, ${ }^{32} \mathrm{P}$ was given $72 \mathrm{~h}$ before induction of ischemia (20). The lack of a change in the specific activity of both total and individual phospholipid species (Fig. 3) eliminated this as a possibility.

The next mechanism evaluated to explain the BBM phospholipid alterations was ischemia-induced loss of the ability of cells to maintain surface membrane polarity. Maintenance of surface membrane polarity is essential for epithelial cells to accomplish net transcellular transport. Recent evidence indicates that epithelial tight junctions are required for maintenance of epithelial polarity, and, therefore, play an essential role in maintaining the lipid and protein differences between apical and BLM. Rabito et al. (26) showed dissociation of tight junctions in confluent LLC-PK 1 cells using calcium-free media lead to apical alkaline phosphatase migration beyond the BBM until it covered the entire cell surface. Dragsten et al. (27), using fluorescent membrane probes, showed that membrane-bound lectins and lipid probes could not pass through the tight junction region. 
Finally, Imhof et al. (28) have shown that a monoclonal antibody to MDCK epithelial cells causes loosening of tight junctions and leads to loss of surface membrane polarity. Since renal proximal tubule cells BBM and BLM differ markedly in proteins (29), receptors (30), electrical resistance (31), and lipids (15), in vivo loss of polarity could lead to large alterations in membrane composition.

The changes noted in ischemic BBM lipids are in the direction expected (increased phosphatidylcholine and phosphatidylinositol and decreased sphingomyelin, phosphatidylserine, and cholesterol) if the BLM were to equilibrate with the BBM during ischemia. The increase in NaK-ATPase specific activity and enrichment in the ischemic BBM fraction is also compatible with this event. Alternatively, the increase in BBM NaK-ATPase and alterations in lipid composition could have occurred as a result of increased BLM contamination of the BBM fraction. To investigate these possibilities, NaK-ATPase was determined cytochemically in rapidly fixed cortical slices, thus avoiding possible membrane isolation artifacts. These studies clearly showed (Figs. 4 and 5) that NaK-ATPase specific reaction product is present in ischemic but not in control apical microvilli and luminal membranes. It therefore seemed that proteins as well as lipids might move from the basolateral membrane to the brush border surface. Hence, we postulate that the increase in ischemic BBM NaK-ATPase was due to loss of surface membrane polarity.

The final possibility to be tested in this study was that the reaction product of $\mathrm{NaK}-\mathrm{ATPase}$ visualized in the cellular area of ischemic BBM was due to free-floating membrane fragments of sloughed BLM. This was examined by using continuous sucrose gradients to separate BBM and BLM. Control BBM and BLM enzymatic markers could be separated into two overlapping peaks with different densities (Fig. 6). The enzyme markers for BBM and BLM in the ischemic BBM fraction, however, had superimposable activity profiles, suggesting that this fraction consisted of homogenous membrane population. Furthermore, the large shift (Fig. 7) in the ischemic-BBM NaK-ATPase profile toward the BBM enzyme marker and away from the ischemic BLM NaK-ATPase profile supports the concept that NaKATPase in the ischemic BBM fraction is actually within BBM and not a contaminant. Also, the ischemic BBM enzymatic marker profile was shifted to the left (towards the control BLM profile) (Fig. 6), indicating that the BBM is more like the BLM in density characteristics. This could come about if the BLM combined with the BBM during ischemia due to loss of surface membrane polarity. The lipid data in Table II also support this concept, and may be the reason for the shift. Therefore, it seems likely that the reaction product of NaK-ATPase visualized cytochemically in luminal membrane fragments after ischemia is localized within BBM and is due to loss of the cell's ability to maintain surface membrane polarity during ischemia. However, although the data taken together are highly suggestive that loss of epithelial polarity does occur during ischemia, contamination of the BBM fraction cannot be entirely ruled out.

The mechanism accounting for loss of surface membrane polarity during ischemia was not evaluated in this study. Recent studies, however, suggest that tight junctions are necessary for maintenance of epithelial polarity (26-28). We noted (unpublished observations) that tight junctions are severely diminished after $30 \mathrm{~min}$ of ischemia to isolated proximal tubule segments. Ziomels et al. (32) has shown that pharmacologically induced depletion of intracellular ATP results in enhanced redistribution of apical marker enzymes over the entire plasma membrane in isolated intestinal epithelial cells. They also showed that drugs known to alter membrane potential had a similar effect. Both cellular ATP depletion (33) and alterations in membrane potential (3) are known to occur during ischemia, and could play a role in tight junction dissociation. Finally, alterations in cellular calcium concentrations may lead to tight junction dissociation (26).

We conclude, therefore, that during renal ischemia it is likely that proximal tubule cells are unable to maintain surface membrane polarity. This results in at least partial equilibration of BBM and BLM, leading to large alterations in the BBM protein (increased NaK-ATPase) and lipid composition. Flow of BLM into the BBM could also explain the increase in ischemic BBM protein recovery and the decrease in ischemic BLM recovery. Why the BBM was primarily affected is not known. However, this equilibration may provide a mechanism for the cell to maintain an intact surface membrane as the ischemic BBM is being lost into the lumen.

\section{Acknowledgments}

We would like to thank Ruth Breckon for her excellent technical assistance and Daisy Rodarte for the excellent typing of this manuscript. We are also indebted to $\mathrm{V}$. Burric and $\mathrm{H}$. Robinson for their willing assistance.

This work was supported in part by the Veterans Administration, through an Associate Investigator Fellowship, and through a National Kidney Foundation Fellowship award to Dr. Molitoris, and by a grant from the National Institutes of Health (AM 15851).

\section{References}

1. Venkatachalam, M. A., D. B. Jones, and H. G. Rennke. 1981. Mechanism of proximal tubule brush border loss and regeneration following mild renal ischemia. Lab. Invest. 45:355-365.

2. Benard, D. B., and N. G. Levinsky. 1978. Tubular leakage and obstruction after renal ischemia: structural-functional correlations. Kidney Int. 13:208-222.

3. Hanley, M. J. 1980. Isolated nephron segments in a rabbit model of ischemic acute renal failure. Am. J. Physiol. 239:F17-F23.

4. Johnston, P. A., H. Rennke, and N. G. Levinsky. 1984. Recovery of proximal tubular function from ischemia. Am. J. Physiol. 246:F159F166.

5. Matthys, E., Y. Patel, J. Kreisberg, J. H. Stewart, and M. Venkatachalam. 1984. Lipid alterations induced by renal ischemia: pathogenic factor in membrane damage. Kidney Int. 26:153-161.

6. Siegel, M. B., L. M. Lowenstein, and N. G. Levinsky. 1979. Choline uptake into renal phospholipids following renal ischemia in rats. Circ. Res. 44:62-67.

7. Chien, K. R., J. Abrams, A. Serroni, J. T. Martin, and J. L. Farber. 1978. Accelerated phospholipid degradation and associated membrane dysfunction in irreversible, ischemic liver cell injury. J. Biol. Chem. 253: 4809-4817.

8. Shaikh, N. A., and E. Downar. 1981. Time course of changes in porcine myocardium phospholipid levels during ischemia: an assessment of the lysolipid hypothesis. Circ. Res. 49:316-325.

9. Shier, W. T., and D. J. DuBourdieu. 1982. Role of phospholipid hydrolysis in the mechanism of toxic cell death by calcium and ionophore A23187. Biochem. Biophys. Res. Commun. 109:106-108.

10. Paddock, J. K., W. Lada, and L. M. Lowenstein. 1981. Regeneration of the renal brush border after renal ischemia in rats. Am. J. Physiol. 241:F28-F33.

11. Farias, R. N., B. Bloj, R. D. Morero, F. Sineriz, and R. E. Trucco. 1975. Regulation of allosteric membrane-bound enzymes through 
changes in membrane lipid composition. Biochim. Biophys. Acta. 415: 231-251.

12. Sandermann, H. A., Jr. 1978. Regulation of membrane enzymes by lipids. Biochim. Biophys. Acta. 515:210-237.

13. Green, D. E., M. Fry, and G. A. Blondin. 1980. Phospholipids as the molecular instruments of ion and solute transport in biological membranes. Proc. Natl. Acad. Sci. USA. 77:257-261.

14. Cullis, P. R., B. deKruijff, M. J. Hope, R. Nayar, and S. L. Schmid. 1980. Phospholipids and membrane transport. Can. J. Biochem. 58: 1091-1100.

15. Molitoris, B. A., and F. R. Simon. 1985. Renal cortical brush border and basolateral membranes: cholesterol and phospholipid composition and relative turnover. J. Membr. Biol. 83:207-215.

16. Eveloff, J., R. Kinne, and W. B. Kinter. 1979. p-Aminohippuric acid transport into brush border vesicles isolated from flounder kidney. Am. J. Physiol. 237:F291-F298.

17. Lowry, O. H., N. J. Rosebrough, A. L. Farr, and R. J. Randall. 1951. Protein measurement with the folin phenol reagent. J. Biol. Chem. 193:265-275.

18. Bligh, E. G., and W. J. Dyer. 1969. A rapid method of total lipid extraction and purification. Can. J. Biochem. Physiol. 37:911-917.

19. Ames, B. N., and D. T. Dubin. 1960. The role of polyamines in the neutralization of bacteriophage deoxyribonucleic acid. J. Biol. Chem. 235:769-775.

20. Molitoris, B. A., and F. R. Simon. 1985. Brush border and basolateral membrane phospholipid composition is controlled by differences in individual phospholipid synthetic rates. Am. Fed. Clin. Res. 33:493a. (Abstr.)

21. Ernst, S. A. 1972. Transport adenosine triphosphatase cytochemistry II. Cytochemical localization of ouabain-sensitive, potassium dependent phosphatase activity in the secretory epithelium of the arian salt gland. 20:23-38.

22. Mayahara, H., K. Fujimoto, I. Ando, and K. Ogawa. 1980. A new one-step method for the cytochemical localization of ouabain-sen- sitive, potassium-dependent p-nitrophenylphosphatase activity. Histochem. J. 67:125-138.

23. Anderson, R. J., J. A. Gordon, J. Kim, L. M. Peterson, and P. A. Gross. 1982. Renal concentration defect following nonologuric acute renal failure in the rat. Kidney Int. 21:583-591.

24. Tyson, C. A., H. V. Zonde, and D. E. Green. 1976. Phospholipids as ionophores. J. Biol. Chem. 251:1326-1332.

25. Somermeyer, M. G., T. C. Knauss, J. M. Weinberg, and D. H. Humes. 1983. Characterization of $\mathrm{Ca}^{2+}$ transport in rat renal brush border membranes and its modulation by phosphatidic acid. Biochem. J. 214: 37-46.

26. Rabito, C. A., J. I. Kreisberg, and D. Wright. 1984. Alkaline phosphatase and glutamyl transpeptidase as polarization markers during the organization of LLC-PK, cells into an epithelial membrane. J. Biol. Chem. 259:574-582.

27. Dragsten, P. R., J. S. Handler, and R. Blumenthal. 1982. Fluorescent membrane probes and the mechanism of maintenance of cellular asymmetry in epithelia. Fed. Proc. 41:48-53.

28. Imhof, B. A., H. P. Vollmers, S. L. Goodman, and W. Birchmeier. 1983. Cell-cell interaction and polarity of epithelial cells: specific pertubation using a monoclonal antibody. Cell. 35:667-675.

29. Barac-Nieto, M., H. Murer, and R. Kinne. 1982. Asymmetry in the transport of lactate by basolateral and brush border membranes of the rat kidney cortex. Pfluegers Arch. 392:366-371.

30. Taylor, Z., D. S. Emmanouel, and A. I. Katz. 1982. Insulin binding and degradation by luminal and basolateral tubular membranes from rabbit kidney. J. Clin. Invest. 69:1136-1146.

31. Fromter, E. 1979. Solute transport across epithelia: what can we learn from micropuncture studies on kidney tubules? J. Physiol. 288:131.

32. Ziomek, C. A., S. Schulman, and M. Edidin. 1980. Redistribution of membrane proteins in isolated mouse intestinal epithelial cells. J. Cell Biol. 86:849-857.

33. Warnick, C. T., and H. M. Lazarus. 1981. Recovery of nucleotide levels after cell injury. Can. J. Biochem. 59:116-121. 